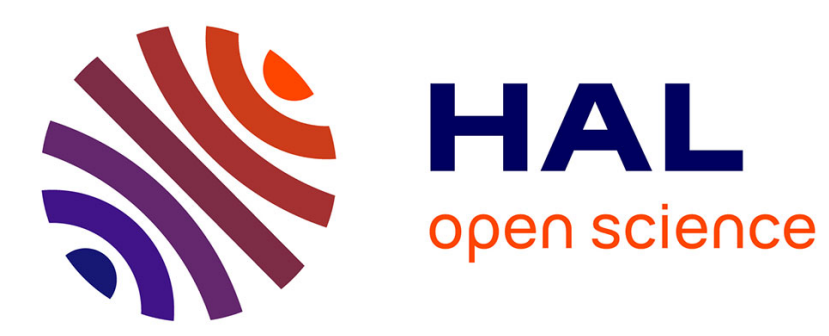

\title{
Free and laterally-nudged Antarctic climate of an Atmospheric general Circulation Model
}

Christophe Genthon, Gerhard Krinner, Emmanuel Cosme

\section{To cite this version:}

Christophe Genthon, Gerhard Krinner, Emmanuel Cosme. Free and laterally-nudged Antarctic climate of an Atmospheric general Circulation Model. Monthly Weather Review, 2002, 130, pp.16011616. 10.1175/1520-0493(2002)1302.0.CO;2 . hal-00203651

\section{HAL Id: hal-00203651 \\ https://hal.science/hal-00203651}

Submitted on 24 Feb 2020

HAL is a multi-disciplinary open access archive for the deposit and dissemination of scientific research documents, whether they are published or not. The documents may come from teaching and research institutions in France or abroad, or from public or private research centers.
L'archive ouverte pluridisciplinaire HAL, est destinée au dépôt et à la diffusion de documents scientifiques de niveau recherche, publiés ou non, émanant des établissements d'enseignement et de recherche français ou étrangers, des laboratoires publics ou privés. 


\title{
Free and Laterally Nudged Antarctic Climate of an Atmospheric General Circulation Model
}

\author{
Christophe Genthon, Gerhard Krinner, and Emmanuel Cosme \\ Laboratoire de Glaciologie et Géophysique de l'Environnement, CNRS/OSUG, Saint Martin d'Hères, France
}

\begin{abstract}
Because many of the synoptic cyclones south of the $60^{\circ} \mathrm{S}$ parallel originate from $60^{\circ} \mathrm{S}$ and lower latitudes, nudging an atmospheric general circulation model (AGCM) with meteorological analyses at the periphery of the Antarctic region may be expected to exert a strong control on the atmospheric circulation inside the region. Here, the ECMWF reanalyses are used to nudge the atmospheric circulation of the Laboratoire de Météorologie Dynamique Zoom (LMDZ) stretched-grid AGCM in a 15-yr simulation spanning the $1979-93$ period. The horizontal resolution (grid spacing) in the model reaches $\sim 100 \mathrm{~km}$ south of $60^{\circ} \mathrm{S}$. Nudging is exerted along the $60^{\circ} \mathrm{S}$ parallel, and this is called lateral nudging for the Antarctic region. Nudging is also performed farther north, near $50^{\circ}$ and $40^{\circ} \mathrm{S}$, but this is not essential for the results discussed here. Surface pressure and winds in the atmospheric column are nudged without relaxation to maximize control by the meteorological analyses, at the expense of some "noise" confined to the latitudes where nudging is exerted. The performances of lateral nudging are evaluated with respect to station observations, the free (unnudged) model, the ECMWF reanalyses, and in limited instances with respect to nudging the surface pressure only. It is shown that the free model has limited but persistent surface pressure and geopotential defects in the Antarctic region, which are efficiently corrected by lateral nudging. Also, the laterally nudged simulations confirm, and to some extent correct, a geopotential deficiency of the ECMWF reanalyses over the east Antarctic continent previously identified by others. The monthly mean variability of surface climate at several stations along a coast-to-pole transect is analyzed. A significant fraction of the observed variability of surface pressure and temperature is reproduced. The fraction is often less than in the reanalyses. However, the differences are not large considering that the nudged model is forced at distances of hundreds to thousands of kilometers whereas the reanalyses are forced at much shorter distances, in principle right at each station site by the very station data. The variability of surface wind is significantly less well reproduced than that of pressure and temperature in both the nudged model and the reanalyses. Carefully adjusted polar physics in the LMDZ model seems to compensate for a distant observational constraint in the cases when the nudged model results appear similar or even superior to the reanalyses. Lateral nudging is less computationally intensive than global nudging, and it induces realistic variability and chronology while leaving full expression of the model physics in the region of interest. Laterally nudging an AGCM with meteorological analyses can offer complementary value over the analyses themselves, not only by producing additional atmospheric information not available from the analyses, but also by correcting possible regional defects in the analyses.
\end{abstract}

\section{Introduction}

An atmospheric general circulation model (AGCM) run over periods longer than a few days produces meteorological information in the climate sense, that is, information that may (and should) statistically but not chronologically resemble the real atmospheric circulation. Here and throughout the paper, chronology refers to variability at various timescales, which sequentially coincides and thus correlates with actual observations. Exploiting statistics, rather than chronological information, requires that data series are long enough to ad-

Corresponding author address: Christophe Genthon, Laboratoire de Glaciologie et Géophysique de l'Environnement, 54 Rue Molière, B.P. 96, F-38402 Saint Martin d'Hères Cedex, France.

E-mail: genthon@glaciog.ujf-grenoble.fr equately sample means, variability, and trends of interest. As a consequence, the verification and exploitation of AGCM climate results often require long and/or ensemble runs. In addition, the validation and utility of even long runs may be limited if the available series of observations are short or incomplete. Chronology, on the other hand, would allows direct event-by-event comparison and validation.

Also, although they are global models, AGCMs are often used for regional studies of the atmospheric circulation and climate. This is the case in particular, but certainly not exclusively, when evaluating the regional signature and impact of global climate change. Regional climate is determined by regional processes and boundary conditions as well as by atmospheric circulation features outside the region of interest itself. For instance, regional precipitation is determined both by local ther- 
modynamical processes (e.g., radiative cooling, convective instability, topographic uplift within the region) and by external circulation characteristics (e.g., dynamic convergence at the periphery). Sorting out internal and external contributions to analyze regional climate, or even to simply diagnose the sources of a regional deficiency in an AGCM, is generally not an easy task.

The two points made above about AGCMs, the lack of chronological information to compare with observation on the one hand, and the difficulty of sorting out local and external forcing of regional climate features on the other hand, may be both addressed by assimilation of observational data. Generally speaking, assimilation is a combination of observations and of mathematical formulations of physical laws to build an optimal picture of the real world (Talagrand 1997). In the context of climate modeling, data assimilation is a generic term for the many methods used to force a model toward realizations that are compatible, not only with the model physics and boundary conditions, but also with the observations when and where they are available. In particular, continuous assimilation of observations through time can force a realistic chronology in a model, to an extent that varies with the strength of the observational constraint. This is clearly relevant to the first point raised above. Probably the simplest method of data assimilation in an AGCM is the so-called nudging, or Newtonian relaxation of model variables toward observed variables of the atmospheric circulation (e.g., Jeuken et al. 1996). If data assimilation, for example, nudging, is performed at the periphery of a region of particular interest, then the atmospheric circulation is constrained at the periphery and for the nudged variables. The constraint can be expected to decrease progressively in the interior of the region as distance from the periphery increases, and in principle the model is free for the variables that are not nudged. Therefore, some processes in the interior of the region may be entirely determined by the model whereas others at the periphery and to some extent in the interior are constrained by nudging. This is relevant to the second point raised above.

Meteorological analyses are built using complex and computationaly intensive four-dimensional data assimilation methods which, in practice, are only remotely related to the simple nudging technique. The meteorological analyses produced by large weather forecasting centers like the European Centre for Medium-Range Weather Forecasts (ECMWF) are global with fine spatial (currently less than $100 \mathrm{~km}$ ) and temporal $(6 \mathrm{~h})$ resolution. Thus, because full spatial and temporal coverage is available, meteorological analyses rather than direct observations can be preferred for nudging the atmospheric circulation of AGCMs (Jeuken et al. 1996), keeping in mind that analyses are not observations and may have biases. Nudging with observations or meteorological analyses, and thus tentatively correcting atmospheric circulation errors and forcing realistic chronology in an AGCM, has also been used to analyze the distributions and history of tracers and chemical species in models (Feichter and Lohmann 1999; Hourdin and Issartel 2000).

We present here the results of an AGCM simulation in which meteorological analyses are used to nudge the peripheral circulation of the Antarctic region. The Antarctic circumpolar atmospheric circulation is characterized by successions of low pressure systems revolving eastward around the Antarctic ice sheet. From the accumulation of low pressure systems results the wellknown Antarctic trough, the band of lowest zonal mean pressure on Earth at about $65^{\circ}-68^{\circ} \mathrm{S}$, with monthly mean values reaching $980 \mathrm{hPa}$ in austral spring (King and Turner 1997). Many of the depressions actually develop at lower latitude, near $60^{\circ} \mathrm{S}$ or farther north (King and Turner 1997), then spiral toward the Antarctic continent. Therefore, one may expect that by forcing the atmospheric circulation near $60^{\circ} \mathrm{S}$, one largely impacts on the atmospheric circulation at higher latitudes even if the model is kept entirely free of forcing inside the Antarctic region itself. Here, the Antarctic region is defined as the region south of $60^{\circ} \mathrm{S}$.

The Laboratoire de Météorologie Dynamique Zoom (LMDZ) AGCM is used in the present study. The LMDZ model is designed in a way that allows stretching of the global grid in order to refine horizontal resolution (grid spacing) over a region of particular interest. An Antarctic "zoom" is used here (Krinner et al. 1997), which is further described along with the model itself in section $2 \mathrm{a}$. The meridional resolution over the Antarctic region reaches 100 km. Fifteen-year Atmospheric Model Intercomparison Project (AMIP) simulations are performed with and without nudging by the ECMWF reanalyses (Gibson et al. 1997). Nudging is performed near $60^{\circ} \mathrm{S}$, as well as at two lower latitudes. This is referred to as lateral nudging for the Antarctic region. Only winds and surface pressure are nudged. The simulations and the nudging method are detailed in section $2 \mathrm{~b}$. Several aspects of the mean global and Antarctic atmospheric circulation in the free (not nudged) and in the laterally nudged simulation are analyzed in section 3 . In section 4 , the monthly mean variability of surface climate at several stations along a coast-to-pole transect is analyzed. To assess the performance in reproducing the monthly chronology, the fraction of the observed variability that is reconstructed by the laterally nudged model is evaluated through correlations with the observations. The amplitude of this variability is also evaluated. For comparison, the same evaluations are performed on ECMWF meteorological analyses that are in principle, but in practice not necessarily, forced right at each station site by the very station data. Results from sections 3 and 4 are summarized and concluded in section 5 .

\section{Experimental setting: Model, nudging, and simulations}

\section{a. The LMDZ AGCM and Antarctic zoom}

The LMDZ AGCM is a model developed by the Laboratoire de Météorologie Dynamique (LMD, Paris, 
France), inherited from a series of models dating back to the original work of Sadourny and Laval (1984). In the model, a dynamic framework resolves the atmospheric primitive equations on an Arakawa $\mathrm{C}$ grid, and a complete physical package describes subgrid processes including turbulence and convection, atmospheric and soil hydrology including clouds and precipitation, and radiation transfer. The model took the name LMDZ when a provision for stretching the grid and thus "zooming" (refining) the horizontal resolution over regions of particular interest was implemented. A first version of the LMDZ model was validated and used with particular interest and zoom over the Antarctic region by Krinner et al. (1997). Differences with the Krinner et al. (1997) version include the following: a mixed sigma-pressure vertical discretization, whereby the lower levels are described in sigma coordinates and the higher levels in pressure coordinates with a smooth transition in between; a mass flux parameterization for moist convection; a larger number of grid points in longitude (96 instead of 72) and latitude (72 instead of 64) and a larger number of vertical layers (19 instead of 15); and a different distribution of grid points in latitude (discussed below).

The improvements developed in Krinner et al. (1997) for polar climate modeling (boundary layer fluxes, sea ice fraction, Antarctic topography and orography, and snow albedo) in a previous version of the model are also implemented in the current version. Vertical discretization is chosen to favor resolution in the boundary layer and thus, hopefully, the simulation of turbulent fluxes and katabatic winds, which are essential features of the climate of the Antarctic ice sheet. At sea level, the mean elevation of the first six layers above the surface are approximately 12, 50, 125, 270, 540, and 980 $\mathrm{m}$. The 10th layer is in the midtroposphere $(\sim 5600 \mathrm{~m})$, the 15th layer is in the higher troposphere or lower stratosphere $(\sim 15000 \mathrm{~m})$, and the top layer is at about $30000 \mathrm{~m}$.

Because the Antarctic continent is roughly axially symmetrical around the South Pole, grid stretching in the zonal direction is not justified for our study. In addition, because the meridians converge at the poles, even a modest nominal grid spacing of $3.75^{\circ}$ in longitude results in quite high geographical resolution at high latitudes: $200 \mathrm{~km}$ at $60^{\circ} \mathrm{S}, 140 \mathrm{~km}$ at $70^{\circ} \mathrm{S}, 100 \mathrm{~km}$ at $75^{\circ} \mathrm{S}$, and $70 \mathrm{~km}$ at $80^{\circ} \mathrm{S}$. In practice, such resolution can only be reached with a time step small enough to ensure numerical stability. This is not realized in regular grid AGCMs when a time step is selected to ensure stability in the low and midlatitudes. A zonal Fourier (or another kind of) filter is applied at high latitudes to smooth out instabilities, a procedure that in practice degrades zonal resolution. With such a filter, the LMDZ model with 96 $\times 72$ regularly distributed grid points can be run with a 4-min time step for the dynamics (a 30-min time step is customarily used for the physics). Here we use a 90s time step, which provides access to the true geograph-

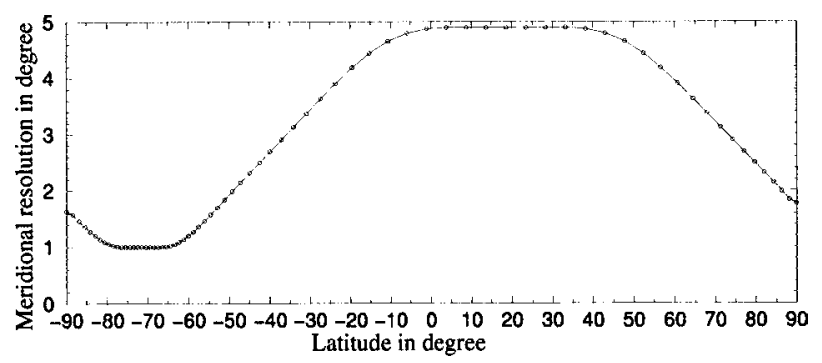

FIG. 1. Meridional resolution (grid spacing) as a function of latitude (negative latitude for the Southern Hemisphere).

ical zonal resolution up to $75^{\circ} \mathrm{S}$. Meridional resolution is increased accordingly over the Antarctic region by stretching the grid along the latitudes as shown in Fig. 1. Resolution is almost regular and slightly less than $1^{\circ}$ in the $65^{\circ}-75^{\circ} \mathrm{S}$ region, which, except for mountains, is the region where the mean coastal slope is largest and where high resolution is thus particularly important. Meridional grid spacing increases almost linearly from $60^{\circ} \mathrm{S}$ to the equator and remains at about $6^{\circ}$ in much of the low and midlatitudes of the Northern Hemisphere. Grid spacing decreases again near the North Pole to limit grid anisotropy in the north polar region.

In spite of a small time step, and because the number of grid points is low compared to a model that would be uniformly fine with a $1^{\circ}$ resolution over the Antarctic region and elsewhere, computing cost is moderate. Results presented here are from 15-yr (AMIP II boundary conditions for 1979-93) simulations with the free and the nudged models.

\section{b. Nudging and simulations}

Traditionally, nudging a model is relaxing the model results toward observations (or analyses) at given intervals (Jeuken et al. 1996). For a nudged variable $X$,

$$
X_{n}=X_{m}+C_{N}\left(X_{o}-X_{m}\right),
$$

where $X_{m}$ is the value of $X$ produced by the free model between two nudging steps, $X_{o}$ is the observation value at nudging time step, and $X_{n}$ is the value of $X$ after the nudging step. In addition, $C_{N}$ is a nudging factor of value between 0 (no nudging, free model) and 1 (absolute nudging).

Here, we use the ECMWF reanalyses (ERA; Gibson et al. 1997) to nudge the atmospheric circulation near $60^{\circ} \mathrm{S}$ (exactly at $60.03^{\circ} \mathrm{S}$, the nearest model latitude) of the LMDZ model with an Antarctic zoom as described in section $2 \mathrm{a}$. The analyses of zonal and meridional wind and of surface pressure are used. The analyses are interpolated to each of the 96 zonal grid points along the $60^{\circ} \mathrm{S}$ parallel. Because a staggered $\mathrm{C}$ grid is used, the zonal wind and the pressure are interpolated on staggered longitudes. For the same reason, the meridional wind is interpolated on the same zonal grid points as pressure, but along the $60.62^{\circ} \mathrm{S}$ parallel. Because the 


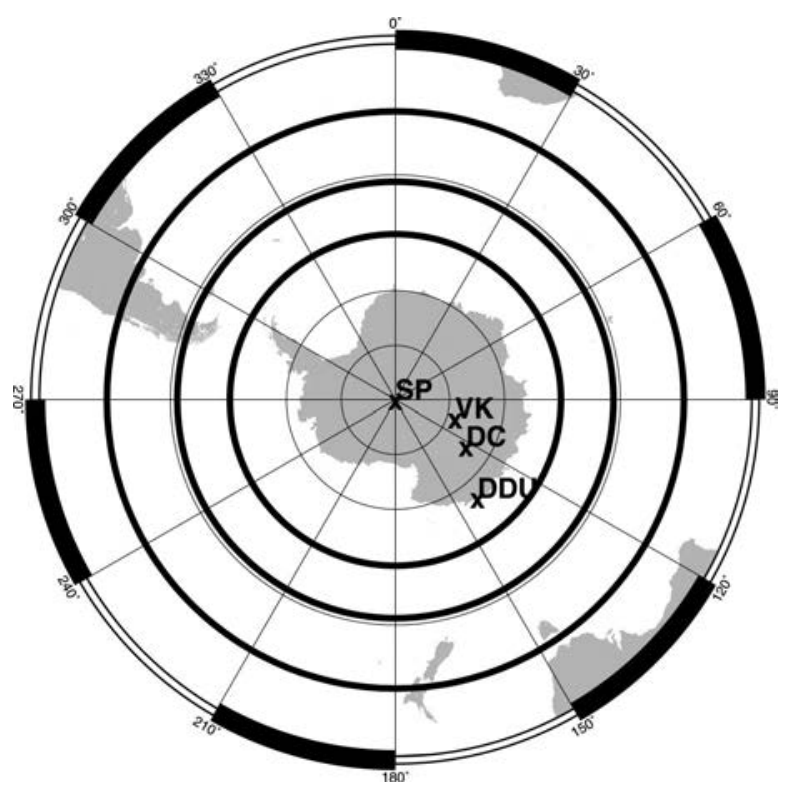

FIG. 2. The nudged parallels at $60.02^{\circ}, 51.13^{\circ}$, and $39.92^{\circ} \mathrm{S}$ (bold circles). Surface pressure and zonal winds are nudged along these parallels. Meridional winds are nudged slightly south of these parallels due to the staggered model grid. The locations of stations DDU, DC, VK, and SP (see text) are also shown. Latitude circles (thin circles) are every $10^{\circ}$.

ECMWF AGCM is a spectral model, horizontal interpolation is spectral. Winds are extracted on the 1000-, 925-, 850-, 700-, 500-, 400-, 300-, 250-, 200-, 150-, and $100-\mathrm{hPa}$ levels. Vertical linear interpolation is performed at each time step and at each nudged model grid point to provide wind at each of the model levels. In principle, because the $60^{\circ} \mathrm{S}$ parallel runs over the ocean at all longitudes, no topographic correction is necessary for surface pressure. However, the ECMWF model is spectral and the elevation of the surface of the ocean is thus not consistently zero. Surface pressure is corrected accordingly using the hydrostatic equation. In fact, in the results presented here, the LMDZ atmospheric circulation is also nudged near the $50^{\circ} \mathrm{S}\left(\right.$ at $51.13^{\circ} \mathrm{S}$ ) and the $40^{\circ} \mathrm{S}$ (at $39.92^{\circ} \mathrm{S}$ ) parallels. Along these parallels, which partially run over continents and mountain ranges, corrections for surface topography differences between the model and the analyses are more important and may be sources of errors. Experiments have shown that forcing at latitudes other than $60^{\circ} \mathrm{S}$ is not essential for Antarctic studies although it slightly improves the rendering of the atmospheric circulation. In fact, we anticipate (but we do not further discuss here) using the lateral nudging approach for Antarctic studies of tracers and chemicals (Genthon and Armengaud 1995; Cosme et al. 2002, manuscript submitted to J. Geophys. Res.) with sources in the midlatitudes. Atmospheric transport in and from the midlatitudes should benefit from nudging in the midlatitudes. It should be noted that nudging in the midlatitudes does not prevent two-way communication (exchange of mass or energy) between the high
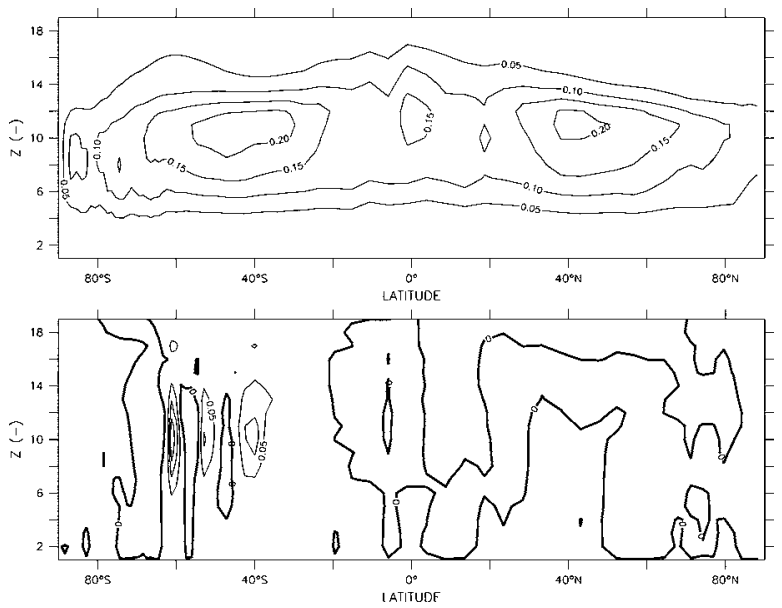

FIG. 3. Standard deviation of vertical wind simulated for Oct 1993. (top) Simulation with the model free of nudging (free model). (bottom) Difference between a nudged and a free model simulation. Vertical scale: model $\sigma$ levels (see section 2a for an approximate conversion to altitude). Unit: $\mathrm{Pa} \mathrm{s}^{-1}$. Isoline every $0.05 \mathrm{~Pa} \mathrm{~s}^{-1}$. The zero isoline is bold.

southern latitudes and the rest of the globe. The map shown in Fig. 2 illustrates where nudging is performed.

Reanalyses are available every $6 \mathrm{~h}$ over the 1979-93 period. Winds and pressure are linearly interpolated in time in order to nudge the model at each dynamic time step, that is, every $90 \mathrm{~s}$. Continuous forcing contributes to ensuring stability of the nudged model by keeping the nudged model close to a dynamic balance and thus avoiding shocks and the development of spurious gravity waves. The additional computing time due to nudging is negligible compared to the CPU resources used by the AGCM itself. In addition, compared to global nudging as done, for instance in Jeuken et al. (1996), the volume of analysis data to be extracted, stored, read, and interpolated is considerably reduced in the case of lateral nudging. Several preliminary experiments have been carried out to determine a nudging constant $C_{N}$. The best control by the nudged variables is clearly obtained when the constant is 1 , that is, with absolute nudging. Absolute forcing is generally avoided in the case of global nudging in order to leave the model some degrees of freedom (Jeuken et al. 1996). Lateral nudging leaves the model all its degrees of freedom within the region of interest. Experiments have shown that the model can sustain absolute lateral forcing without developing large amounts of noise or instabilities. The variance of vertical wind is a sensitive measure of numerical noise in models. In particular, excessive variance may be the signature of spurious gravity waves triggered by adjustment shocks, for example, in response to strong nudging as done here. Figure 3 shows that in austral spring, at a time of the year when the stochastic synoptic activity around the Antarctic region is high (King and Turner 1997), and thus corrections by nudging may be particularly strong, the standard de- 

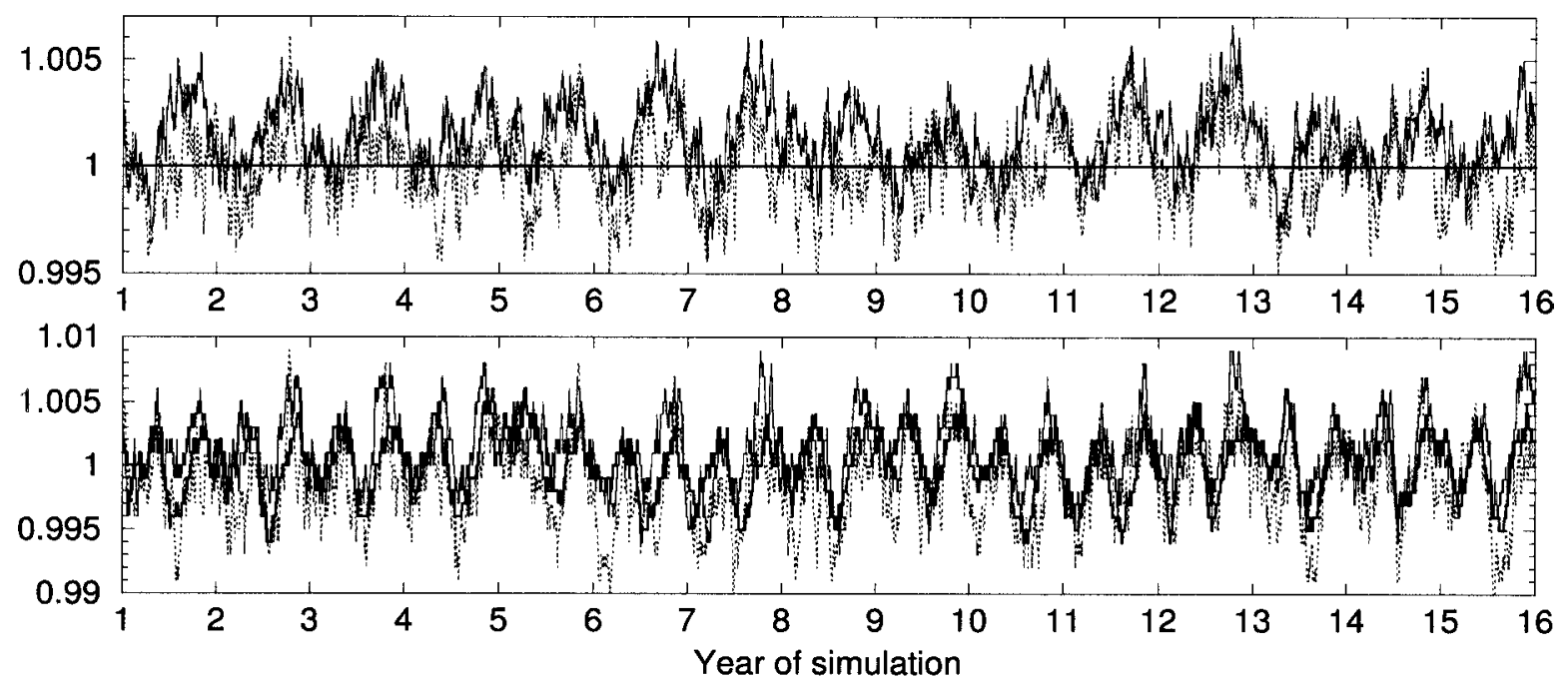

FIG. 4. Daily normalized (no unit) globally integrated atmospheric mass (top) and angular momentum (bottom) in the free model (thick continuous line), the fully (surface pressure and winds) nudged model (thin continuous line), and the partially (pressure only) nudged model (dotted line).

viation of vertical wind is broadly similar in a nudged and in a free simulation. The largest differences are confined near the nudging latitudes in the midtroposphere. There is no sign that this noise propagates significantly to either the Antarctic region or to the lower latitudes and the Northern Hemisphere. Absolute lateral forcing is thus used here to maximize lateral control by the analyses. Trade-offs between control and noise may be searched for and preferred if applications call for a smooth circulation even at the nudging latitudes.

It must be stressed that only the dynamics of the circumpolar circulation are nudged. In particular, temperature and moisture remain entirely free and fully consistent with the internal physics (radiation, convection, evaporation, condensation, etc.) of the model, even at the nudging latitudes. Lateral thermodynamic and/or hydrodynamic nudging is technically possible and it may be tested in a later work. However, preliminary experiments have shown that absolute nudging is not recommended for temperature. This is due to slight inconsistencies between the physics in the nudged model and in the ECMWF model producing the nudging (analyzed) variables. Because convective instability is a threshold process, these inconsistencies result in permanent convection near the nudged latitudes [see also Jeuken et al. (1996) for a similar problem with global nudging]. It remains to be verified that a nudging factor ensuring a fair trade-off between control by nudging and acceptable behavior of the nudged model exists, considering in particular that purely dynamic lateral nudging already exerts a strong control on temperature in the Antarctic region (section $4 b$ ).

Two main simulations have been made, each preceded by a discarded 6-month spinup run, then run over the full 1979-93 period using the AMIP sea surface temperature and sea ice coverage as boundary conditions.
Lateral nudging is the only difference between the two simulations. The free model simulation provides a validation over the Antarctic region as well as a control against which the laterally nudged model simulation can be compared. A third simulation in which nudging is limited to surface pressure (but propagates into the atmosphere due to the mixed sigma-pressure vertical coordinate) has also been carried out and is only briefly referred to.

\section{The free and nudged global and Antarctic atmospheric circulation}

The mean sea level pressure (SLP), with some particular interest for the Antarctic trough, and the mean 500-hPa geopotential height are used to characterize the impact of nudging on the tropospheric circulation. Although in this paper, lateral nudging is mainly advocated and analyzed for applications in the Antarctic region, it is important that global aspects are also assessed. In particular, it is important to illustrate that nudging limited to the southern mid- and high latitudes does not perturb the global state and balance of the atmosphere.

\section{a. The global atmospheric circulation}

Climate models are expected to verify basic global conservation laws. Obviously, nudging the surface pressure and the winds affects the conservation of total atmospheric mass and the global conservation of momentum in the model. When the model is not nudged, atmospheric mass is strictly conserved, and atmospheric momentum is conserved to a good approximation (Fig. 4), consistent with momentum exchange with the surface. In the nudged models, the total mass fluctuates within $\sim 0.2 \%$ (standard deviation, translating into $\sim 2$ 


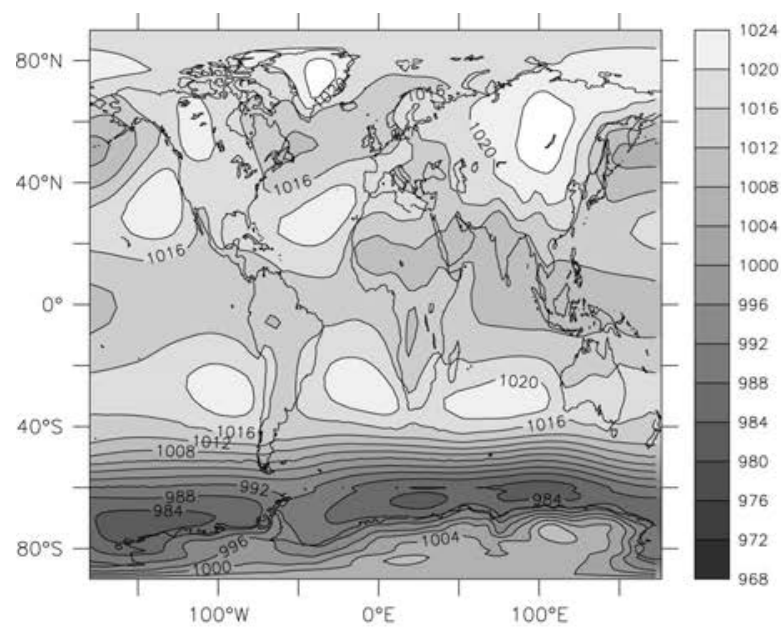

NUDGED

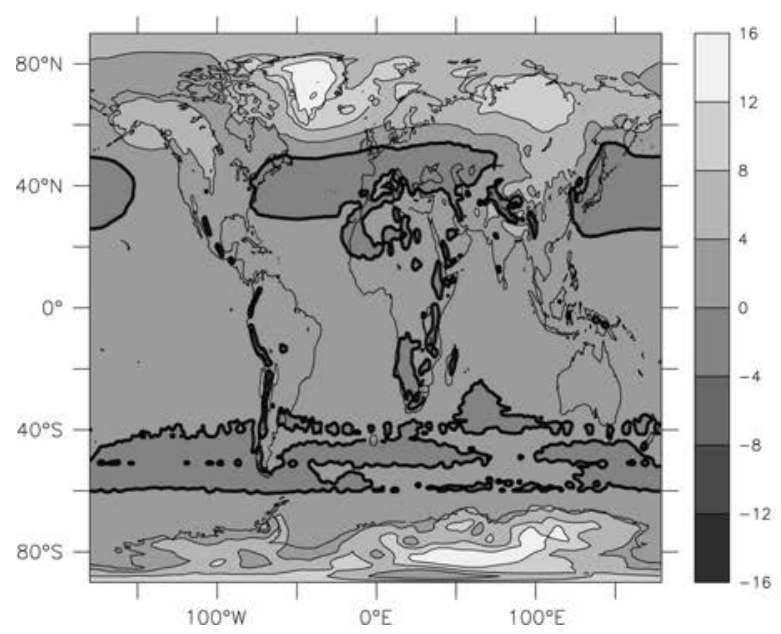

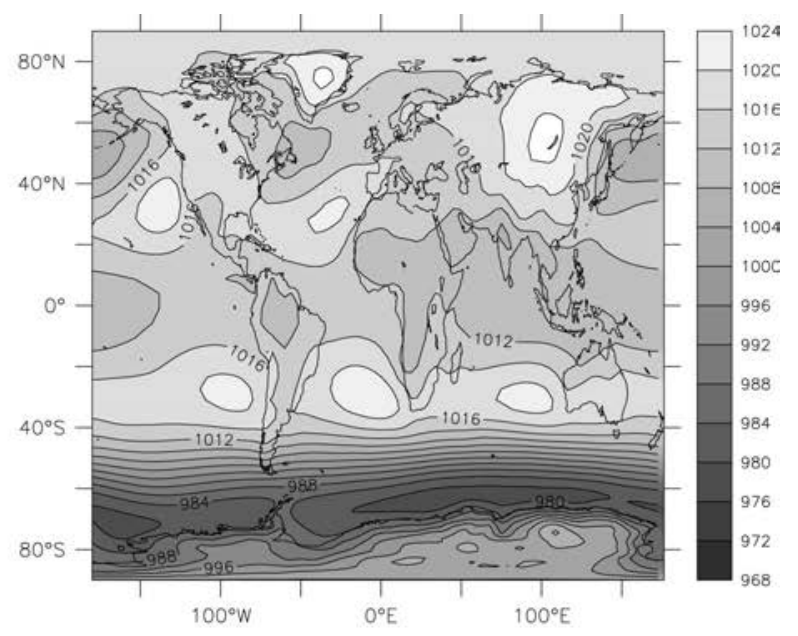

FREE

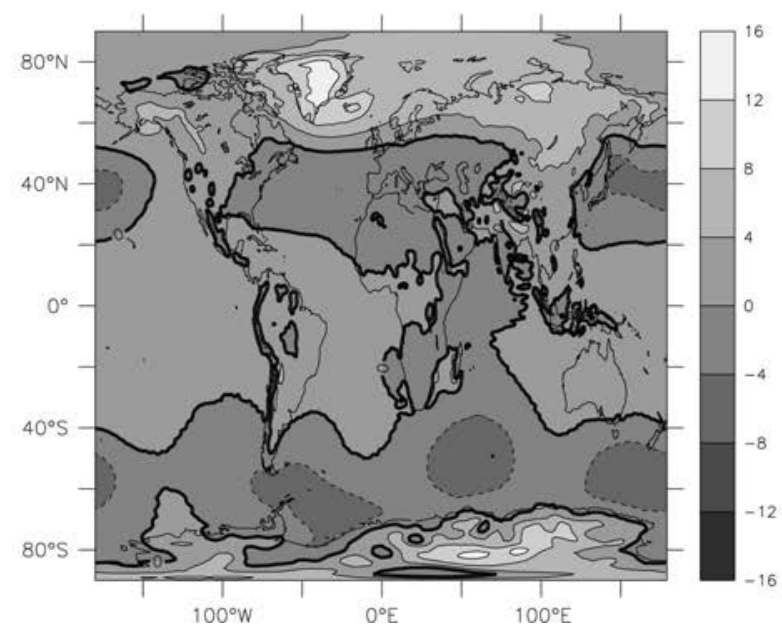

FIG. 5. Global annual mean (1979-93) sea level pressure in (left) the nudged model and (right) the free model. Upper panels in hPa. Lower panels show the difference, model minus reanalyses in hPa. Isolines every $4 \mathrm{hPa}$, dashed isolines for negative values, and the zero isoline is bold.

hPa on the mean surface pressure) of the mean (Fig. 4). In particular, a seasonal cycle of amplitude of $0.3 \%$ $0.4 \%(3-4 \mathrm{hPa})$ suggests some disagreement between the model and the analyses on how to seasonally distribute atmospheric mass on the globe. The global mean mass adjusts slightly, and very quickly at the beginning of the 6-month spinup period. On average over the 15 $\mathrm{yr}$ of simulation, the mean mass is only $0.14 \%$ larger ( $0.08 \%$ lower) in the fully (pressure only) nudged model than in the free model. This must be kept in mind when comparing pressure or geopotential with the free model or with the reanalyses. More importantly, there is no long-term trend in either of the nudged simulations (Fig.
4). Thus, no attempt is made to artificially correct the fluctuations and enforce mass conservation. Global momentum is not significantly affected, nor are the conserved thermodynamic quantities (energy, enstrophy, entropy). Global quasi-conservation does not imply that nudging does not affect the distribution of mass or momentum within the global atmosphere. SLP is the variable that best illustrates mass distribution on the globe.

Maps of the annual mean SLP in the nudged and free models (Fig. 5) show a clear impact of nudging in the mid- and high southern latitudes. It may also suggest that the atmospheric circulation is slightly affected north of the nudged latitudes. This is to some extent confirmed 

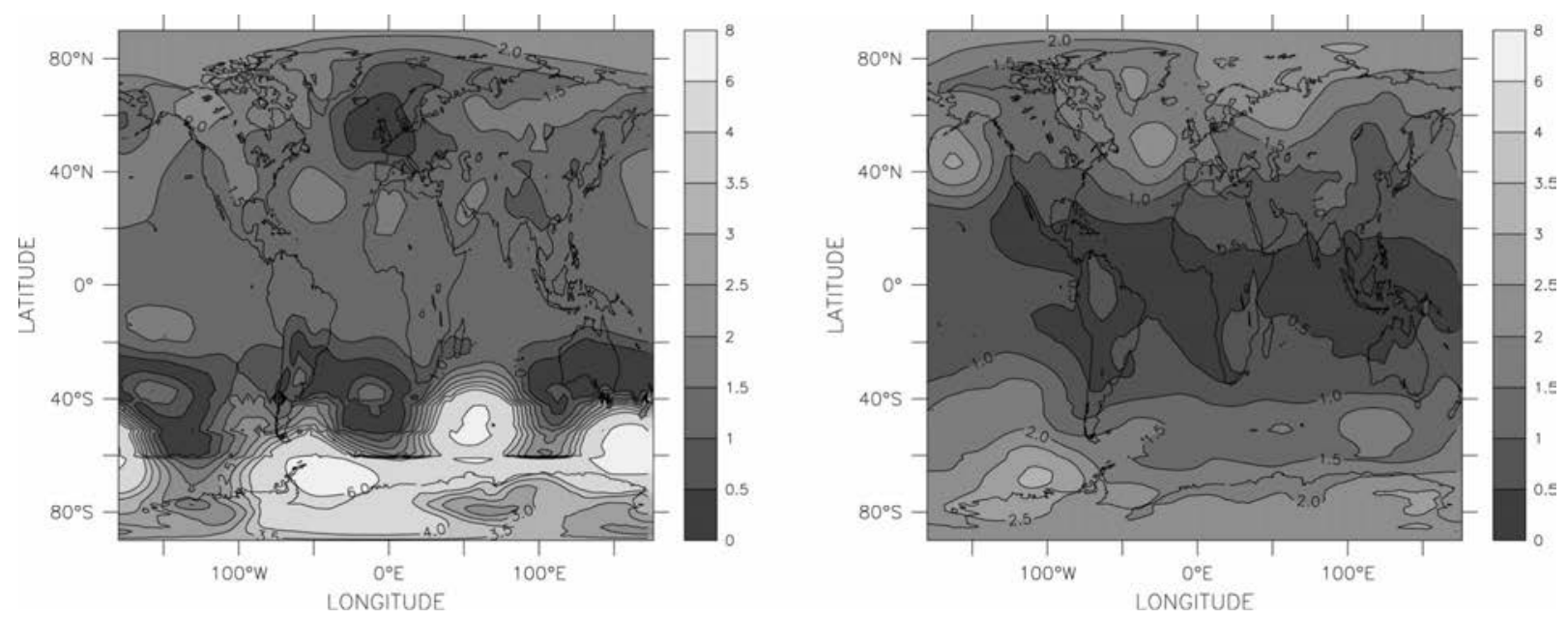

FIG. 6. Module of the difference in mean sea level pressure between the nudged and the free models (left) and interannual standard deviation of sea level pressure averaged in the free and nudged models (right). Unit: $\mathrm{hPa}$.

by Fig. 6, which compares the differences in the free and forced models with the mean interannual standard deviation of the SLP. The interannual standard deviation is computed as

$$
s_{y}(\mathrm{SLP})=\sqrt{\frac{\sum_{y=1979}^{1993}(\mathrm{msl}(y)-\overline{\mathrm{msl}})^{2}}{15}},
$$

where $\operatorname{msl}(y)$ is the annual mean SLP of year $y$ and $\overline{\mathrm{msl}}$ is the SLP averaged over the $15 \mathrm{yr}$ of simulation. The absolute value of the (nudged minus free) model difference is much larger than $s_{y}$ (SLP) and thus highly significant in much of the mid- and high southern latitudes. It is less so elsewhere. The model difference is only slightly larger than $s_{y}$ (SLP) in the Tropics, and mostly smaller or of similar magnitude in the extratropics and at higher latitudes in the Northern Hemisphere. However, $s_{y}$ (SLP) itself is affected by nudging. Figure 7 compares $s_{y}$ (SLP) in the free and nudged models and shows, in particular, that interannual variability in the North Atlantic and in the high northern latitudes is affected by nudging in the southern mid- and high latitudes, probably by a global adjustment of the largescale atmospheric circulation in response to forcing in the south. One cannot fully rule out that this is an artifact of the nudging method, which was shown to introduce some variability of the global atmospheric mass in the model. However, this is not likely because $s_{y}(\mathrm{SLP})$ is locally affected in the Northern Hemisphere rather than uniformly increased on the globe. In any case, the Antarctic zoom makes the simulations analyzed here less than ideal to study such interhemispheric teleconnection. In particular, it would be appropriate to verify that a similar teleconnection can be found in a regular-grid version of the model, and it would be even more convincing if it can be obtained in other, similarly nudged AGCMs. If so, then the importance of the southern at- mospheric circulation in the global climate may be emphasized. This aspect, which might be a valuable application of regionally limited nudging of an global climate model, is not further discussed here.

The free model has biases in the (low resolution) Northern Hemisphere. The surface pressure is too high in the Atlantic and Eurasian Arctic regions and too low in the mid-Pacific region (Fig. 5). The Northern Hemisphere biases are not corrected in the nudged model. On the other hand, the biases of the southern mid- and high latitudes are very efficiently corrected. This is an expected result in the latitude band where nudging is implemented $\left(40^{\circ}-60^{\circ} \mathrm{S}\right)$. This is also not a surprising result at higher latitudes due to the importance for the Antarctic circulation of the synoptic activity at the periphery as discussed in the introduction.

\section{b. The Antarctic atmospheric circulation}

Figure 5 shows that the mean SLP in the high southern latitudes is too low in the free model, a bias found in other high-resolution models (e.g., Météo-France 1998) although here it extends to relatively low latitudes. In addition, the zonal, broadly ternary structure of the trough is not sufficiently marked in the free model. The pattern of anomaly with respect to the reanalyses (Fig. 5) is reminiscent of cases of weak semiannual oscillation (SAO). In particular, similar anomalies are reported by van den Broeke (2000) during years of weak SAO in long series of meteorological analyses. The anomalies are interpreted as the result of a failure of the circumpolar pressure belt to move north- and westward during the SAO expansion phases. Figure 7 shows a maximum of interannual variability reaching more than $3 \mathrm{hPa}$ near the Amundsen Sea sector $\left(90^{\circ}-140^{\circ} \mathrm{W}\right)$ of the Antarctic region in both the nudged and the free models. This is confirmed in the reanalyses. Elsewhere in the Antarctic region, nudging slightly reduces the interannual vari- 


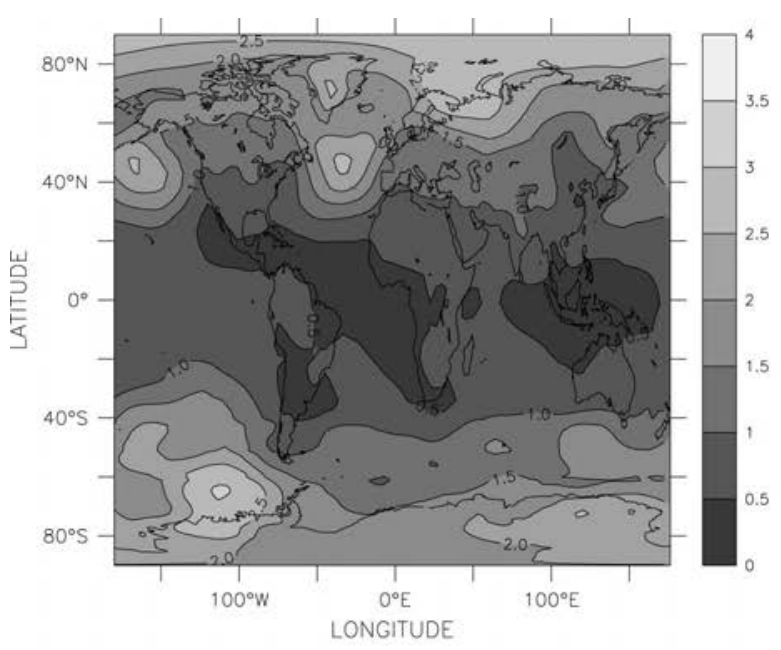

NUDGED

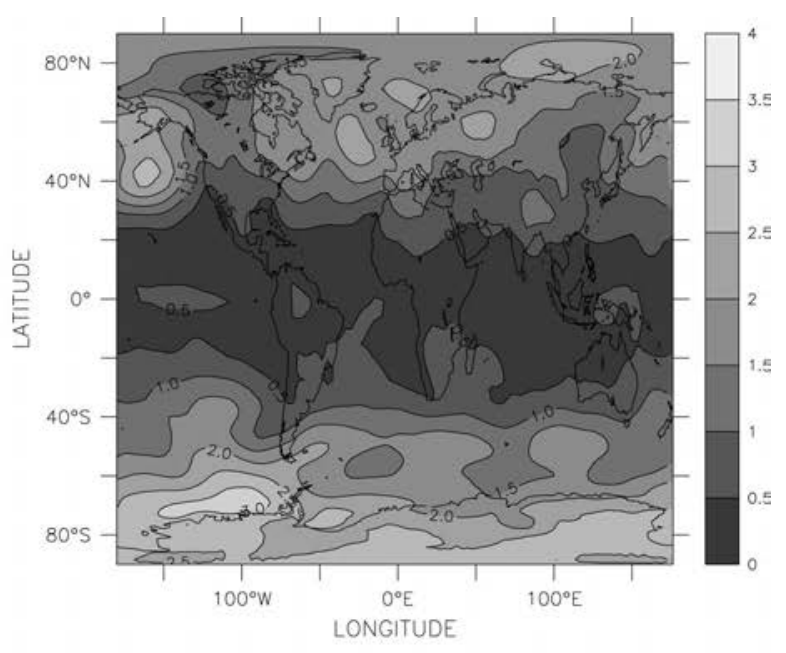

FREE

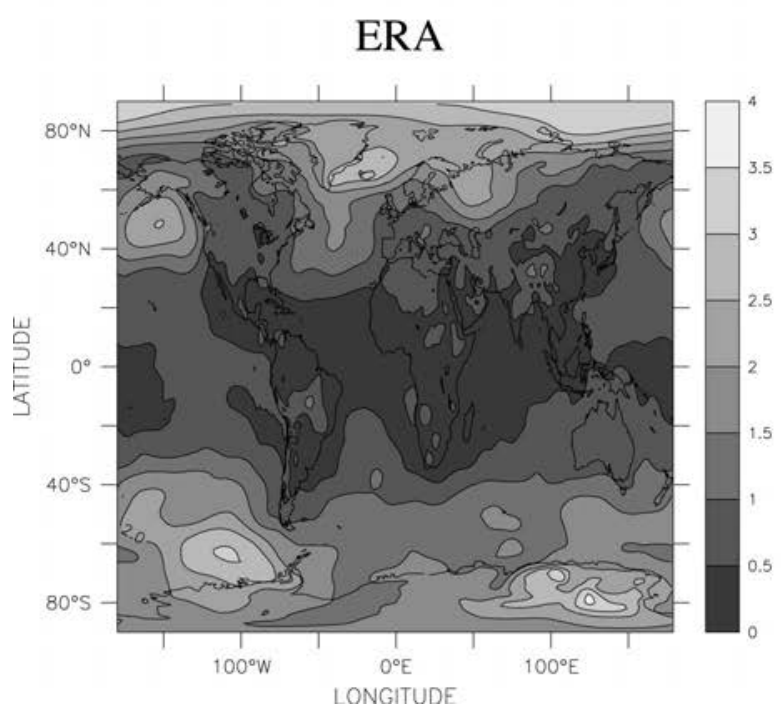

FIG. 7. Interannual standard deviation of sea level pressure in the nudged and free models and in the reanalyses (ERA). Unit: hPa.

ability compared to the free model. This is a direct consequence of the variability being smaller in the reanalyses than in the free model (Fig. 7). Variability of the Antarctic pressure in the free and nudged models and in the reanalyses is further analyzed in section 4 .

Figure 8, which shows the seasonal march of the Antarctic trough, indicates that much of the zonal mean pressure bias in the free model (Fig. 5) is an austral winter and spring bias. This is consistent with a stronger adjustment of the global mean mass, in response to nudging, in the second half of the calender year (Fig. 4). The Antarctic trough and its seasonality are features of the Antarctic climate that AGCMs often fail to reproduce well. For instance, Briegleb and Bromwich (1998) report the results of two versions of the National
Center for Atmospheric Research's (NCAR) Community Climate Model (CCM) AGCM. In the older version, the depth of the trough in austral winter and spring is overestimated, very much like in the free model here and in a previous version of the LMDZ model described by Krinner et al. (1997). In the newer version of the NCAR CCM model, the winter and spring bias is largely corrected but in summer and fall the pressure is too low.

The annual march of pressure in the trough in the nudged model is quite reasonable (Fig. 8). Although the trough is largely too low in the free model, it remains slightly larger all year long in the nudged model than in the reanalyses. This is most probably partially related to a global mean mass adjustment reported in section 3a. Also, lateral nudging has a weak impact on the sea- 

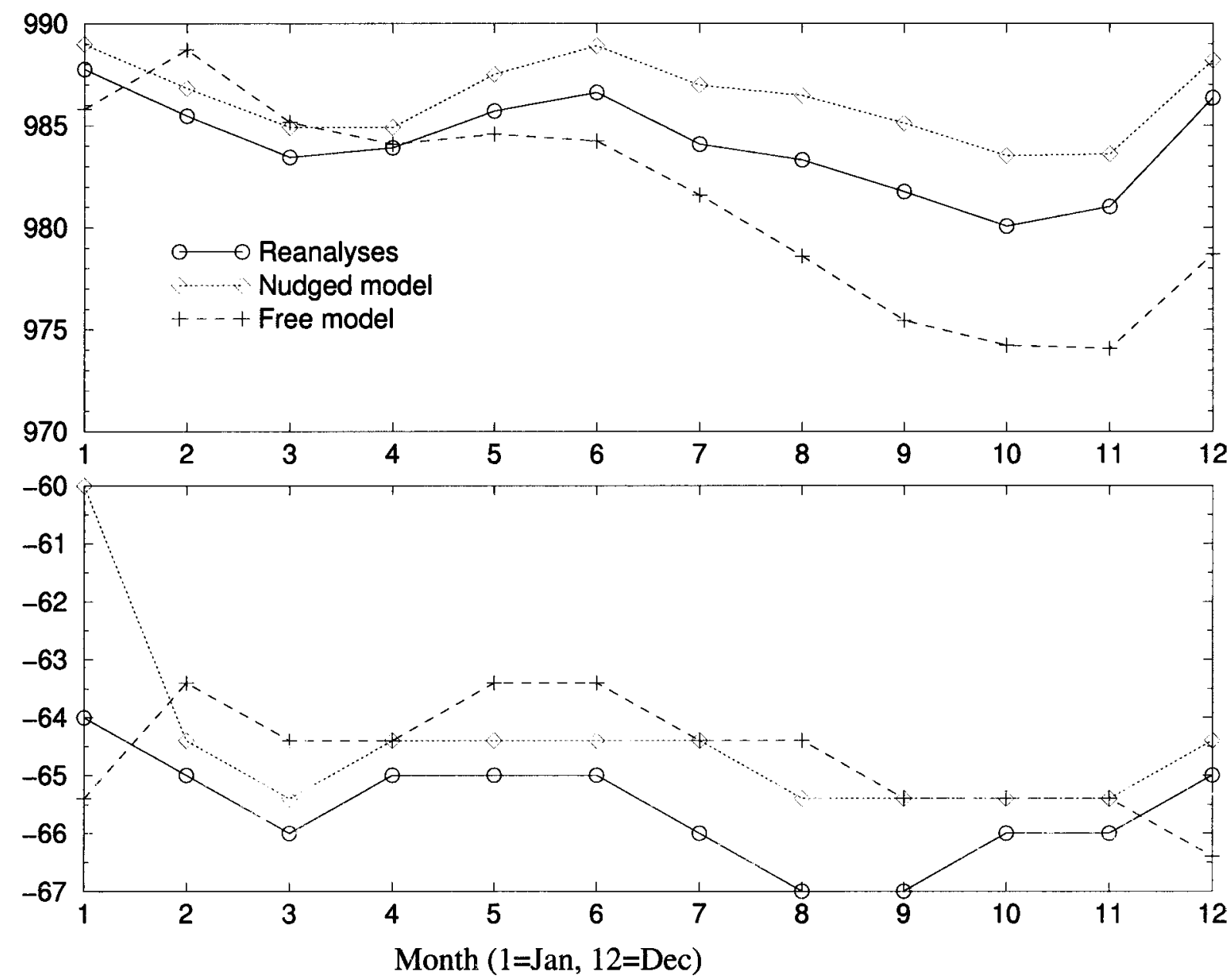

FIG. 8. Annual march of the Antarctic circumpolar trough, defined as the minimum of zonally averaged mean sea level pressure. (top) The minimum pressure in the trough, in $\mathrm{hPa}$. (bottom) The latitude of the trough, in ${ }^{\circ}$ (negative for south).

sonal march of the latitude of the trough (Fig. 8), which remains on average almost $2^{\circ}$ (i.e., two grid points) north of the reanalyses results. A similar problem is found in other AGCMs (e.g., Briegleb and Bromwich 1998). In addition, the spring component of the SAO, the October-December northward migration of the trough after reaching its southernmost position in late winter, is missing in the free model. In this respect, nudging reinforces the SAO.

The pressure extrapolated to sea level has little significance over the Antarctic ice sheet where the mean surface altitude is about $2000 \mathrm{~m}$. In particular, apparent biases with respect to the reanalyses in the SLP over the east Antarctic continent (Fig. 5) largely reflect differences in the extrapolation probably related to differences in the surface climate (e.g., temperature). This is confirmed by the 500-hPa geopotential height (Fig. 9), which is not affected by such extrapolation problems. In the free model, there is no geographical correlation between the geopotential and the SLP biases with respect to the reanalyses above the ice sheet. On the other hand, the circum-Antarctic geopotential biases correlate with the circum-Antarctic SLP biases, together reflecting the barotropic nature of the insufficiently marked ternary structure. This problem is, again, very efficiently corrected in the nudged model.

A relatively large $(\sim 20 \mathrm{~m}$, reducing to $\sim 15 \mathrm{~m}$ if global mass adjustment is taken into account) geopotential difference with the reanalyses is found on the east Antarctic plateau in the vicinity of the Vostok station $\left(78^{\circ} 27^{\prime} \mathrm{S}, 106^{\circ} 52^{\prime} \mathrm{E}, 3844 \mathrm{~m}\right.$ asl). In fact, Bromwich et al. (2000) report that an incorrect station elevation for Vostok has adversely affected the production of the ECMWF reanalyses throughout the reanalysis period. The elevation error is of the order of $60 \mathrm{~m}$. This is more than the apparent geopotential bias mentioned above for the model laterally nudged with the reanalyzed winds and surface pressure, but just about the value reached in the simulation in which the model is laterally nudged with the surface pressure only (Fig. 9). This result suggests that the station data at Vostok, and any error therein, can affect the analyzed general circulation as far as 


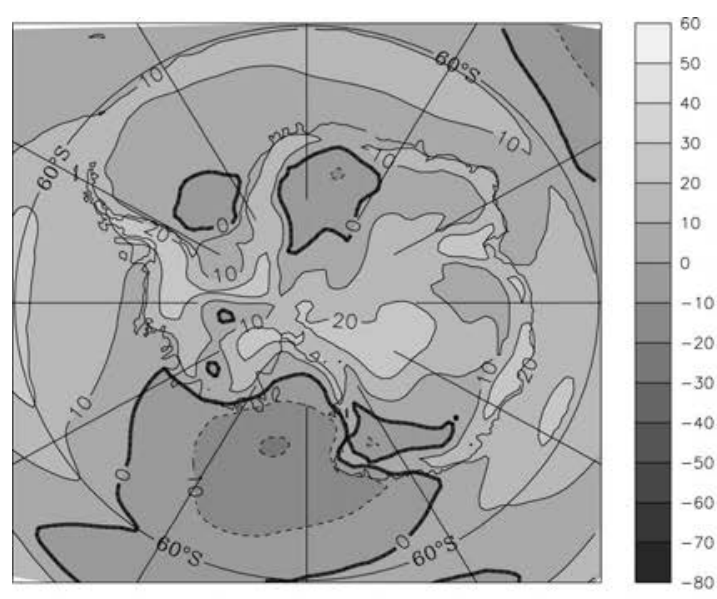

NUDGED

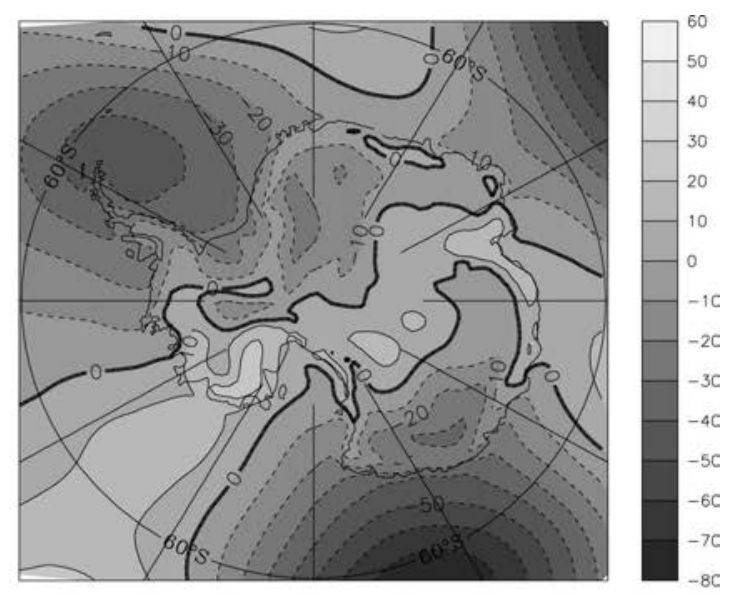

FREE

\section{NUDGED, SP ONLY}

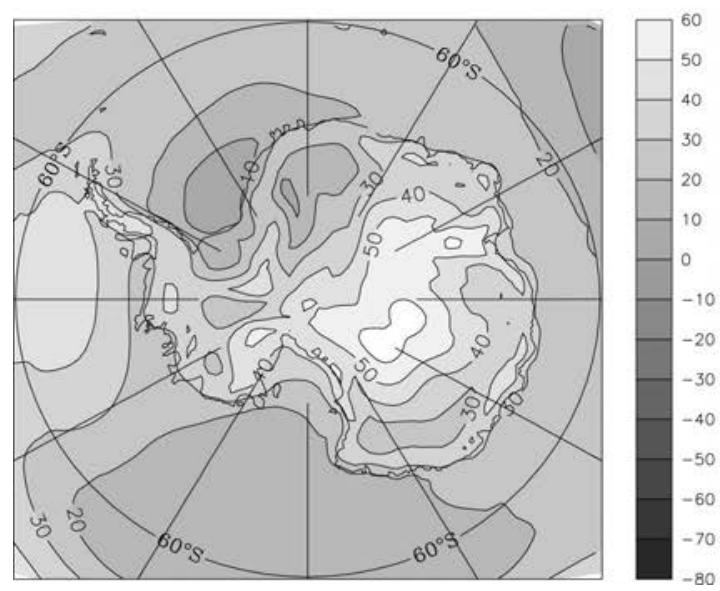

FIG. 9. Difference: model minus analyses of annual mean (1979-93) geopotential height at the 500-hPa level in (upper left) the nudged model, (upper right) free model, and (bottom) partially nudged (surface pressure only) model. Units: m.

the $60^{\circ} \mathrm{S}$ parallel, except for the surface pressure. Surface pressure may remain unaffected because it is constrained by more numerous observations (from automatic weather stations, buoys, ships, etc.) than the free atmospheric circulation. Bromwich et al. (2000) also report that the $500-\mathrm{hPa}$ geopotential in the reanalyses is too low over much of the Antarctic region. They show that operational analyses (less affected by the altitude error at Vostok) are consistently higher than the reanalyses over the circumpolar ocean, and that at a number of circumpolar stations for which radiosonde data are available, the reanalyses are of the order of $20 \mathrm{~m}$ too low at $500 \mathrm{hPa}$. This is again about the value by which they are lower in the reanalyses than in the model nudged with the surface pressure only (Fig. 9). In the main (pressure and wind) laterally nudged simulation, the mean difference with the reanalyses has the same sign but is lower. It thus appears that a picture of the Antarctic atmospheric circulation, which is to some extent, depending on how nudging is done, corrected for biases that affect the very analyses used for nudging, is provided by the nudged AGCM. Obviously, a globally nudged model would not bring any correction.

So far, laterally nudging the Antarctic circulation of an AGCM has proven to bring strong control by the observations in the mid- and high southern latitudes. Some added value over the reanalyses used for nudging is also suggested. This is further illustrated when con- 
TABLE 1. Monthly surface pressure correlation (undetrended/seasonally detrended) between observations and models or reanalyses.

\begin{tabular}{lccl}
\hline \hline Station & LMDZ nudged & Reanalyses & LMDZ free \\
\hline DDU & $0.90 / 0.87$ & $0.97 / 0.96$ & $0.26 /-0.02$ \\
D10 & $0.88 / 0.85$ & $0.94 / 0.93$ & $0.34 / 0.04$ \\
DC & $0.90 / 0.82$ & $0.92 / 0.86$ & $0.35 /-0.09$ \\
VK & $0.88 / 0.73$ & $0.97 / 0.91$ & $0.48 / 0.10$ \\
SP & $0.84 / 0.75$ & $0.95 / 0.90$ & $0.50 / 0.11$ \\
CA & $0.89 / 0.74$ & $0.98 / 0.89$ & $0.51 / 0.05$ \\
\hline
\end{tabular}

sidering monthly and interannual variability of the surface climate at a selection of sites on the Antarctic ice sheet.

\section{Monthly and interannual variability of surface climate in the Wilkes Land sector of the Antarctic ice sheet}

Surface meteorological observations are available along a transect in Wilkes Land running from Dumont d'Urville (DDU, $66^{\circ} 4^{\prime} \mathrm{S}, 140^{\circ} 01^{\prime} \mathrm{E}, 30 \mathrm{~m}$ above sea level) at the coast, through D10 $\left(66^{\circ} 4^{\prime} \mathrm{S}, 139^{\circ} 48^{\prime} \mathrm{E}, 240\right.$ $\mathrm{m})$, Dome C (DC, $\left.74^{\circ} 30^{\prime} \mathrm{S}, 123^{\circ} \mathrm{E}, 3245 \mathrm{~m}\right)$, and Vostok (VK, $78^{\circ} 27^{\prime} \mathrm{S}, 106^{\circ} 52^{\prime} \mathrm{E}, 3488 \mathrm{~m}$ ), to South Pole Amundsen Scott (SP, 90 $\mathrm{S}, 2835 \mathrm{~m}$ ) (Fig. 2). Conventional (at manual weather stations, MWS) observations are or have been taken at DDU, VK, and SP. Automatic weather stations (AWS) are or have been running at D10, DC, and Clean Air (CA) at the South Pole. The South Pole site will be designated by SP or CA depending on whether MWS or AWS data are used. The DDU station is on a small island near (4 km offshore) the Antarctic coast. All other stations are on the ice sheet. The records are not complete over the time period 1979-93, either because the stations have not been continuously operational (DC, D10, and CA AWSs, VK MWS) or because the compiled data are not all available to us. Monthly mean MWS data are obtained from the British Antarctic Survey (BAS) data server (http:// www.nerc-bas.ac.uk/icd/metlog). The core of the database is that of Jones and Limbert (1987), further updated by BAS. The 3-hourly AWS data are obtained from the University of Wisconsin AWS station data server (http:// uwamrc.ssec.wisc.edu/aws/awsproj.html). They are averaged to produce monthly means when a sufficient number (more than $50 \%$ ) of 3-hourly data is available. At least 8 yr of reasonably sampled monthly mean data, not necessarily the same years everywhere, are available at each site within the 1979-93 period. Correlations computed from these series are thus based on $\sim 10^{2}$ samples. If monthly mean data are independent from each other, correlations above $\sim 0.25$ and $\sim 0.20$ have a chance of less than $5 \%$ and $1 \%$ (respectively) of being insignificant. Consecutive monthly mean climate data are not necessarily fully independent. However, autocorrelations of the time series (of either the observations, the analyses, or the model results, after the sea-

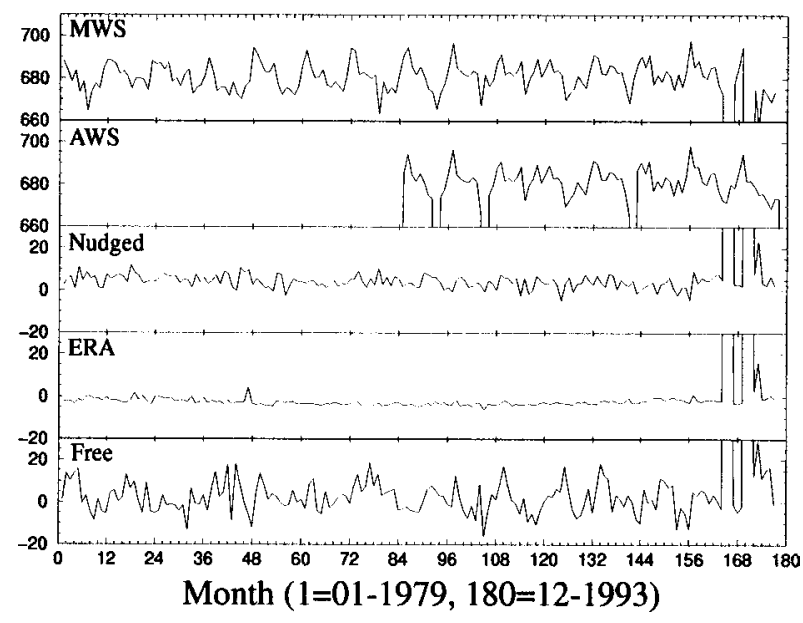

FIG. 10. Time series of surface pressure at the South Pole, in $\mathrm{hPa}$. From top to bottom: MWS (Amundsen Scott, SP) observations, AWS (Clean Air, CA) observations, nudged model minus MWS, reanalyses minus MWS, and free model minus MWS. Values outside scale represent missing observations.

sonal cycle is removed) suggest that monthly mean climate data are largely independent and that full decorrelation occurs within a 2 -month lag. In fact, a 0.50 correlation with only 15 independent samples would still be significant at the $5 \%$ error level. Of the correlations reported here, only the very lowest, below 0.25 , may be insignificant. This is confirmed by the fact that correlations between the observations and the mostly stochastic seasonally detrended variability in the free model are systematically below 0.14 (Tables 1, 3, and 5).

Results from the main (surface pressure and winds) laterally nudged simulation are presented and discussed, with only some hints from the alternate (surface pressure only) laterally nudged simulation. The major statements and conclusions would apply to the simulation with nudging limited to surface pressure, although correlations are then generally slightly lower except for surface wind as discussed in section 4c. Variability and correlations in the reanalyses are also reported for comparison. The reanalyses are, in principle, forced by the very observations with which they are correlated. However, observations may be rejected by the assimilation for various reasons, or even simply not available in the archives for assimilation. Yet, in all cases, the observational constraint is very unlikely to be more distant in the reanalyses than in the nudged model.

\section{a. Surface pressure}

Table 1 shows the correlations of the monthly mean surface pressure between the observations and the nudged model, the reanalyses, and the free model. Figure 10 shows the corresponding monthly time series for the South Pole. Model and reanalyses grid points close to the location of each site are selected for the calculations. Closeness is not the only criterion of selection. 
TABLE 2. Observed and ratio of modeled or reanalyzed to observed standard deviation of monthly surface pressure (undetrended/seasonally detrended).

\begin{tabular}{lccc}
\hline \hline $\begin{array}{c}\text { Station (observed } \\
\text { std dev in hPa) }\end{array}$ & LMDZ nudged & Reanalyses & LMDZ free \\
\hline DDU (5.5/4.7) & $1.08 / 1.03$ & $1.00 / 0.96$ & $1.53 / 1.31$ \\
D10 (5.5/4.6) & $1.10 / 1.06$ & $0.96 / 0.98$ & $1.51 / 1.25$ \\
DC (7.2/5.2) & $1.03 / 1.00$ & $1.03 / 1.10$ & $1.14 / 1.15$ \\
VK (6.8/4.8) & $1.06 / 1.03$ & $1.02 / 1.05$ & $1.23 / 1.26$ \\
SP (6.7/4.6) & $0.95 / 0.91$ & $0.94 / 0.90$ & $1.17 / 1.11$ \\
\hline
\end{tabular}

A grid point nearby having a mean elevation closer to the real station elevation may be preferred to the nearest grid point. Differences in elevation of a few tens of meters are nonetheless possible. At D10, on the costal slope of the ice sheet, the difference can reach several hundreds of meters and must be taken into account when comparing mean surface pressure and temperature. However, variances rather than mean values are discussed here, so no correction is applied. A grid point for which the prescribed surface is oceanic is selected for comparison with DDU data, whereas a nearby continental grid point is selected for comparison with D10 data. In practice, the variability in the observations reported at DDU and at D10 is rather similar, so that different diagnostics at DDU and D10 generally reflect the ocean-continent contrast in the models and in the reanalyses.

Correlations are separately calculated for the MWS (SP) and the AWS (CA) observations at the South Pole, in order to show that shorter samples and missing data (Fig. 10) do not significantly affect the results. On average, the correlations of the observations with the nudged model are high and they do not decrease as distance from the nudging increases (Table 1). However, the correlations for the free model increase with distance from the coast. This is interpreted as a better ability of the free model to reproduce the mean seasonal cycle of surface pressure as its contribution to the total variance becomes stronger farther inland. Correlations between the series detrended for the seasonal cycle are thus also computed and shown in Table 1. The detrended correlations mostly reflect the ability to reproduce the chronology of the intraseasonal monthly variability. The detrended correlations, which are consistently insignificant for the free model, are slightly lower than the raw correlations for the nudged model. They appear to somewhat decrease with distance from $60^{\circ} \mathrm{S}$, but they remain relatively high even at the South Pole. The detrended correlations are consistently lower for the model than for the reanalyses though.

Table 2 compares the model and reanalyses monthly standard deviation of surface pressure

$$
s_{m}(\mathrm{SP})=\sqrt{\frac{\sum_{m=1}^{M}(\mathrm{SP}(m)-\overline{\mathrm{SP}})^{2}}{M}},
$$

TABLE 3. Monthly surface temperature correlation (undetrended/ seasonally detrended) between observations and models or reanalyses.

\begin{tabular}{lccl}
\hline \hline Station & LMDZ nudged & Reanalyses & LMDZ free \\
\hline DDU & $0.96 / 0.76$ & $0.95 / 0.82$ & $0.88 /-0.07$ \\
D10 & $0.94 / 0.74$ & $0.96 / 0.76$ & $0.85 / 0.09$ \\
DC & $0.94 / 0.62$ & $0.97 / 0.62$ & $0.91 /-0.09$ \\
VK & $0.97 / 0.54$ & $0.98 / 0.67$ & $0.95 / 0.06$ \\
SP & $0.96 / 0.37$ & $0.98 / 0.65$ & $0.94 / 0.06$ \\
\hline
\end{tabular}

where $\operatorname{SP}(m)$ is the monthly mean surface pressure of month $m, M$ is the number of months in the observations, and $\overline{\mathrm{SP}}$ is the surface pressure averaged over the $M$ months. In Table 2, $s_{m}(\mathrm{SP})$ for the model and reanalyses is normalized by the corresponding standard deviation in the observations, also given in the table. The free model systematically overestimates both the seasonal and the intraseasonal variability. Seasonal and intraseasonal variability, just like interannual variability (section 3 , Fig. 7), are very efficiently reduced to reasonable values by lateral nudging. The impact of nudging is larger at the coast but this is also where the free model bias is strongest.

\section{b. Surface temperature}

Table 3 shows the correlations for surface temperatures. Recall that there is no assimilation of analyzed atmospheric temperature in the nudged (and, of course, in the free) model. Surface temperature is observed at elevations of $2-3 \mathrm{~m}$ above ground at the stations. This is compared with the $2-\mathrm{m}$ temperature from the reanalyses and with the temperature in the first layer in the model at approximately $10 \mathrm{~m}$. In the case of strong inversion, the vertical temperature gradient near the surface may reach one or several tenths of degrees per meter. Therefore, the model results may slightly underestimate the variability of temperature in winter on the Antarctic plateau. However, no attempt is made to extrapolate the temperature to $2 \mathrm{~m}$ because uncertainties on the temperature profile may result in just about the same level of error. On the other hand, the 2-m (extrapolated, as available in the ECMWF archives), rather than the first-level, reanalyses data are used because this is the level at which surface observations are assimilated. In addition, the first level in the ECMWF model used to produce the reanalyses is more than $20 \mathrm{~m}$ above the surface. Series of surface temperature at SP are shown in Fig. 11.

Undetrended (raw) correlations are higher for surface temperature than for surface pressure. This result mainly indicates that the seasonal cycle is a stronger component of total variance for temperature than for surface pressure, and that the shape (but not necessarily the amplitude) of the seasonal component is relatively well reproduced by even the free model. The raw correlations in the free model are higher inland than at the coast, again reflecting a stronger and well-predicted season- 


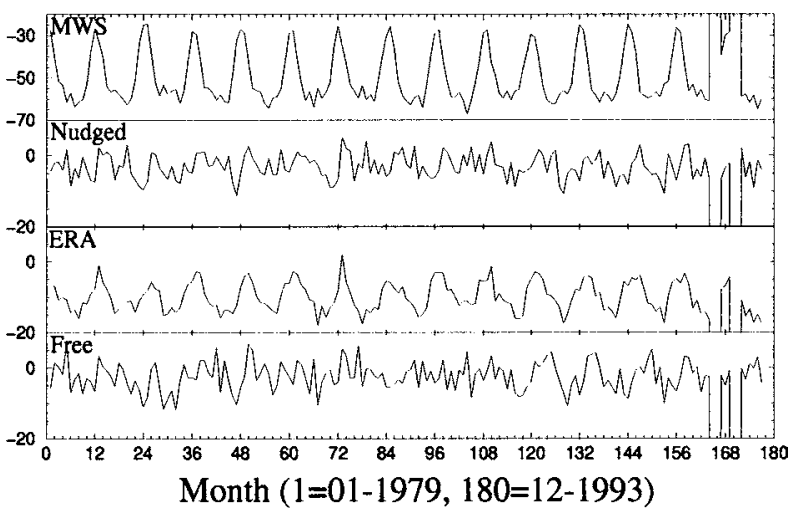

FIG. 11. Time series of surface temperature at the South Pole, in ${ }^{\circ} \mathrm{C}$. From top to bottom: MWS (Amundsen Scott, SP) observations, nudged model minus MWS, reanalyses minus MWS, and free model minus MWS. Values outside scale represent missing observations.

ality inland. The raw correlations are consistently high on the ice sheet, and they are not significantly lower for the nudged model than for the reanalyses. On the other hand, the detrended correlations, both for the model and for the reanalyses, are lower with temperature than with surface pressure. The detrended correlations are consistently insignificant for the free model. For the nudged model, they decrease as distance from the coast increases, to finally reach weakly significant values at SP. Figure 11 illustrates that at such a low correlation level, the amount of reconstructed variability is only weakly larger than in the free model. The detrended correlations for the reanalyses are also larger at the coast than inland, but scores are similar at all three sites on the plateau.

Surface pressure largely reflects the large-scale atmospheric dynamics. Surface temperature reflects, in addition, local boundary layer dynamics, atmospheric thermodynamics, radiation, and more generally the components of AGCMs collectively referred to as the physical parameterizations. Therefore, lower correlation scores for temperature than for pressure may indicate that some of the physical parameterizations do not work very well over the Antarctic ice sheet. In fact, it is remarkable that, although dynamic variables are nudged several hundreds of kilometers away and no thermodynamic variable (e.g., temperature) is nudged, the nudged model reproduces the variability of surface temperature at the coast and even on the plateau (at DC, more than $1500 \mathrm{~km}$ away from the $60^{\circ} \mathrm{S}$ parallel) just as well as the reanalyses. This result may be related to the observation of a winter cold bias on the plateau affecting the reanalyses [e.g., Genthon and Krinner (1998); Fig. 11 shows that the winter cold bias reaches more than $15^{\circ} \mathrm{C}$ at SP], which is the signature of an inappropriate treatment of very stable boundary layers in the ECMWF AGCM. Better accounting of the boundary layer in the LMDZ AGCM due to specific tuning work (Krinner et al. 1997) probably compensates for a lesser constraint by the observations. However, this does
TABLE 4. Observed and ratio of modeled or reanalyzed to observed monthly surface temperature standard deviation (undetrended/seasonally detrended).

\begin{tabular}{lccc}
\hline \hline $\begin{array}{c}\text { Station (observed } \\
\left.\text { std dev in }{ }^{\circ} \mathrm{C}\right)\end{array}$ & LMDZ nudged & Reanalyses & LMDZ free \\
\hline DDU $(5.9 / 2.0)$ & $1.12 / 1.11$ & $1.05 / 1.09$ & $1.03 / 0.97$ \\
D10 $(5.9 / 2.1)$ & $1.04 / 1.25$ & $1.33 / 1.52$ & $0.91 / 1.10$ \\
DC $(12.5 / 2.8)$ & $0.80 / 1.11$ & $0.97 / 0.93$ & $0.80 / 1.10$ \\
VK $(13.4 / 2.7)$ & $0.86 / 0.84$ & $1.02 / 0.79$ & $0.82 / 0.89$ \\
SP $(12.1 / 2.5)$ & $1.00 / 0.93$ & $1.17 / 0.76$ & $0.98 / 1.00$ \\
\hline
\end{tabular}

not appear to be sufficient to compensate for distance as far away as SP. Lower scores for SP and to some extent for VK than for DC might also be related to a larger exposure to air masses from the west (e.g., Hogan et al. 1982) inducing a different sensitivity to lateral nudging.

Nudging tends to slightly increase both the raw and detrended standard deviation everywhere (Table 4). It generally but not systematically brings the model in better agreement with the observations. In addition, the reanalyses do not perform better than the nudged model, or even than the free model, in reproducing the observed amplitude of variability.

\section{c. Surface wind}

Observed surface winds are available to us at AWS, that is, at D10, DC and CA (the SP AWS). Surface wind over the Antarctic ice sheet is determined both by the synoptic activity and by the surface temperature inversion which, when combined with topography, induces katabatic flows. The katabatic contribution is largest in those coastal regions where not only gravity forcing is large (slopes) but also where the flow is channeled and concentrated (valleys). DDU and D10 are well-known sites of strong katabatic winds. Winds are weaker and show less directional constancy on the plateau (King and Turner 1997). Observations of surface winds are reported at an elevation of about $3 \mathrm{~m}$ at AWS. This is compared with the $10-\mathrm{m}$ wind from the reanalyses (as is available in the ECMWF archives) and wind in the lowest layer in the models, also at about $10 \mathrm{~m}$. In a neutral surface layer with a surface roughness length of $0.1 \mathrm{~mm}$ [typical of polar snows according to King and Turner (1997)], wind speed is about $10 \%$ higher at 10 $\mathrm{m}$ than at $3 \mathrm{~m}$. Model and reanalysis winds are thus expected to be slightly larger than observed. Variability could also be somewhat stronger but correlations should not be significantly affected. Like for surface temperature, scores for surface wind reconstruction should be sensitive to the quality of the physical parameterizations.

Both the reanalyses and the nudged model reproduce the wind much less well than the other surface climate variables (Table 5). The correlations are barely or not significant anywhere for the seasonally detrended var- 
TABLE 5. Monthly surface wind correlation (undetrended/seasonally detrended) between observations and models or reanalyses.

\begin{tabular}{lccl}
\hline \hline Station & LMDZ nudged & Reanalyses & LMDZ free \\
\hline D10 & $0.61 / 0.31$ & $0.39 / 0.16$ & $0.49 / 0.01$ \\
DC & $0.16 / 0.15$ & $0.10 / 0.19$ & $0.15 / 0.10$ \\
CA & $0.50 / 0.15$ & $0.71 / 0.55$ & $0.35 /-0.14$ \\
\hline
\end{tabular}

iability, except at CA in the reanalyses. The correlations remain moderate when the seasonal cycle is included. The scores are consistently and surprisingly low at DC. In fact, the cross correlation of the reanalyses and the nudged model over the period for which the observations are available at DC reaches 0.36 . This is weakly significant but much higher than the respective correlations with the observations, suggesting that a common cause may be contributing to limit the performance of the nudged model and the reanalyses at DC. For the model nudged with surface pressure only, both the raw and undetrended correlations with the observations rise to 0.25 . They also significantly increase at CA (0.62/ 0.37; while the impact at D10 is much less). One should not draw strong conclusions here but there is a hint that, in addition to a basic difficulty to reconstruct surface wind compared to surface pressure or temperature, the nudged model may be adversely affected by biases in the nudging variables. The problem is reduced when the winds are not used, and this is reminiscent of consequences on nudged model results of the Vostok bias in the reanalyses discussed in section 3 .

The nudged model, and even the free model for the undetrended variability, perform better than the reanalyses at D10. When nudging is limited to surface pressure, the nudged model does better at DC and slightly less well at CA. These results may again support that more carefully adjusted surface physics in the LMDZ AGCM than in the reanalyses compensates to some extent for distant constraint by observations.

The amplitude of variability of the surface wind (Table 6), like the mean wind itself (not shown), is lower on the plateau than at the coast. The observed raw monthly standard deviation $\left(s_{m}(\mathrm{SW})\right)$ is underestimated by the models and the reanalyses at the coast, and overestimated at DC. At CA, the raw variability is also overestimated in the free model but this is corrected by nudging. The detrended standard deviation is underestimated at the coast and at CA but overestimated at DC. Nudging does not improve the detrended model results.

The general picture emerging for surface wind is that the reanalyses are not superior to the nudged model. However, and unfortunately, no one should really be encouraged to use either the reanalyses or the results of the nudged model to reconstruct monthly variability as observed in the real world. The variability of surface wind appears to be a stringent test for climate models, most probably of the physical parameterizations in these models.
TABLE 6. Observed and ratio of modeled or reanalyzed to observed monthly surface wind standard deviation (undetrended/seasonally detrended).

\begin{tabular}{lccc}
\hline \hline $\begin{array}{l}\text { Station (observed } \\
\text { std dev in } \mathrm{m} \mathrm{s}^{-1} \text { ) }\end{array}$ & LMDZ nudged & Reanalyses & LMDZ free \\
\hline D10 $(1.61 / 1.20)$ & $0.78 / 0.41$ & $0.59 / 0.68$ & $0.81 / 0.39$ \\
DC $(0.64 / 0.59)$ & $1.44 / 1.40$ & $1.47 / 1.09$ & $1.38 / 1.29$ \\
CA $(0.77 / 0.65)$ & $1.09 / 0.70$ & $1.02 / 0.75$ & $1.32 / 0.79$ \\
\hline
\end{tabular}

\section{Summary and conclusions}

A simple and inexpensive method to limit Antarctic atmospheric circulation biases related to lower-latitude circulation deficiencies and to force realistic chronological variability in AGCMs has been described and tested in the LMDZ model. The method consists of nudging analyzed dynamical variables, here the surface pressure and the wind in the atmospheric column from the ECMWF reanalyses, along the periphery of the Antarctic region. This method is termed lateral nudging. Here, nudging is done at three parallels near $60^{\circ}, 50^{\circ}$, and $40^{\circ} \mathrm{S}$, although experiments (not reported here) indicate that the constraint on the two lower latitudes is not essential for the Antarctic circulation itself. Nudging is performed without relaxation. The cost of the method in terms of manpower for implementation, of additional computing cost, and of volume of manipulated data is very reasonable. The method should be straightforwardly applicable to other AGCMs. It may also be applicable to other regions of interest although the broadly circular symmetry of the Antarctic ice sheet and the lack of continent along the $60^{\circ} \mathrm{S}$ parallel make it particularly appropriate and easy to implement for the Antarctic region. To a large extent, lateral nudging may be regarded as a method to apply the same tool, an AGCM, to climate studies for which AGCMs are generally designed, as well as to regional studies more traditionally dedicated to limited area models.

The free (without nudging) model performs relatively well in the Antarctic region, yet a number of biases are noted. The Antarctic trough is too deep in austral spring and summer, and its ternary zonal structure is not sufficiently marked. This is very efficiently corrected by lateral nudging. In addition, the trough is placed $2^{\circ}$ north of its position in the reanalyses, and this is not corrected by nudging. The 500-hPa geopotential in the free model shows biases consistent with the surface pressure biases. A 500-hPa geopotential discrepancy between the reanalyses and the nudged model is located over the east Antarctic plateau near the Vostok station. In fact, this difference reflects a bias in the reanalyses rather than in the model. In this respect, the nudged model may be viewed as providing, in response to lateral nudging, a corrected version of the reanalyzed Antarctic circulation. The correction brought by the nudged model is only partial when full (surface pressure and winds) nudging is performed. The magnitude of the correction is just about the estimated error in the reanalyses when 
nudging is limited to surface pressure. More generally, the Antarctic 500-hPa geopotential is a few decameters higher in the nudged model than in the reanalyses, a result that is also interpreted as a bias of the reanalyses corrected in the nudged model.

Nudging in the mid- and high southern latitudes affects the atmospheric circulation in the Northern Hemisphere, although as expected much less so than in the Antarctic region. The nudged simulation gives hints of interhemispheric teleconnection through an atmospheric bridge. However, the model configuration, with a stretched grid to increase resolution over the Antarctic region at the expense of, particularly, the northern midlatitudes, is not appropriate to further address such a topic here. Nudging tends to decrease variability in the mid- and high southern latitudes, including over the Antarctic continent.

Comparison of model results with observed monthly times series of surface climate variables shows that nudging does bring significant monthly chronological control even in the interior of the ice sheet more than $3000 \mathrm{~km}$ away from the nudged latitudes. The amplitude of the mean monthly variability is also generally improved. As expected, the chronology and variability are generally better reproduced by the reanalyses, which are constrained by the very data they are compared to, or by other observations nearby. Yet, the nudged model performances are not much lower than the reanalyses, even in the interior of the ice sheet far away from the nudging. There are cases in which the nudged model does just as well (e.g., surface temperature on the high plateau) or even better (surface wind at the coast) than the reanalyses. This is possible despite a smaller influence by the observations, if aspects of the physics that determine the surface variables are more accurately reproduced in the LMDZ than in the ECMWF model. Indeed, the LMDZ model was relatively finely tuned for surface polar climate (Krinner et al. 1997) and, in particular, stable boundary layer physics were significantly adjusted.

Why would someone want a reconstruction of the Antarctic atmospheric circulation that is not consistently better than the reanalyses, when the reanalyses are available? Obviously, one may be interested in the aspects that can be better reproduced, or "corrected," in a nudged model, but the prospect goes beyond that. Sensitivity experiments and tentative improvements of an AGCM may be realized at a lesser cost since shorter simulations may be sufficient to characterize variability when chronological time series rather than statistics need to be verified. Realistically constraining the peripheral atmospheric circulation may simplify the search and correction of deficiencies in the interior of the domain of interest. It may also reveal and allow the study of teleconnections between the nudged regions and the rest of the world, not limited to the Antarctic region. Variability and trends in the analyses used to nudge a model may tentatively be confirmed in the nudged mod- el, and the causes (e.g., local changes in the boundary conditions versus changes of the lateral circulation) may be searched for. In the Antarctic region, variability and trends of interest include, for example, the Antarctic Circumpolar Wave, or the mass balance of the ice sheet in relation to sea level.

Finally, the databases that have been archived and made available from analyses and reanalyses, which include not only the analyzed (pressure, wind, temperature, etc.) but also the predicted (precipitation, evaporation, etc.) variables, are large but they do not cover all possible needs. In particular, no information on the chemical composition of the atmosphere is provided. Atmospheric tracers and chemistry modules are increasingly coupled to AGCMs, including the AGCM used here (Cosme et al. 2002, manuscript submitted to $J$. Geophys. Res.). Nudging may be used to force a realistic circulation and chronology in order to better compare the simulated and observed time series of species. This has been done with global nudging (Feichter and Lohmann 1999; Hourdin and Issartel 2000). Because it is inexpensive and leaves freedom to the model physics in the region of interest, lateral nudging should also be considered. These are possible applications for which we have now developed the method and which we intend to explore in the future.

Acknowledgments. This work was undertaken with support by the French Programme National d'Etude de la Dynamique du Climat (Projet "Anthropique") and Programme National de Chimie Atmosphérique (Projet "Soufre aux moyennes et hautes latitudes Sud").

\section{REFERENCES}

Briegleb, B., and D. H. Bromwich, 1998: Polar climate simulation of the NCAR CCM3. J. Climate, 11, 1270-1286.

Bromwich, D. H., A. N. Rogers, P. Kallberg, R. I. Cullather, J. W. C. White, and K. J. Kreutz, 2000: ECMWF analyses and reanalyses depiction of ENSO in Antarctic precipitation. J. Climate, 13, 1406-1420.

Feichter, J., and U. Lohmann, 1999: Can a relaxation technique be used to validate clouds and sulphur species in a GCM? Quart. J. Roy. Meteor. Soc., 125, 1277-1294.

Genthon, C., and A. Armengaud, 1995: GCMs simulations of atmospheric tracers in the polar latitudes: South Pole (Antarctica) and Summit (Greenland) cases. Sci. Total Environ., 161, 101116.

__ , and G. Krinner, 1998: Convergence and disposal of energy and moisture on the Antarctic polar cap from ECMWF analyses and forecasts. J. Climate, 11, 1703-1716.

Gibson, J. K., P. Kallberg, S. Uppala, A. Noumura, A. Hernandez, and E. Serrano, 1997: ERA description. ECMWF Re-analysis Project Rep. Series 1, ECMWF, Reading, United Kingdom, 77 pp.

Hogan, A., S. Barnard, J. Samson, and W. Winters, 1982: The transport of heat, water vapor and particulate matter to the south polar plateau. J. Geophys. Res., 87, 4487-4492.

Hourdin, F., and J.-P. Issartel, 2000: Sub-surface nuclear tests monitoring through the CTBT xenon network. Geophys. Res. Lett., 27, 2245-2248.

Jeuken, A. B., P. C. Siegmund, L. C. Heijboer, J. Feichter, and L. Bengtsson, 1996: On the potential of assimilating meteorological 
analyses in a global climate model for the purpose of model validation. J. Geophys. Res., 101, 16939-16950.

Jones, P. D., and D. W. S. Limbert, 1987: A data bank of Antarctic surface temperature and pressure data. Carbon Dioxide Research Division Tech. Rep. TRO38, 52 pp.

King, J. C., and J. Turner, 1997: Antarctic Meteorology and Climatology. Cambridge University Press, $409 \mathrm{pp}$.

Krinner, G., C. Genthon, Z.-X. Li, and P. Le Van, 1997: Studies of the Antarctic climate with a stretched grid GCM. J. Geophys. Res., 102, 13 731-13 745.

Météo-France, 1998: HIRETYCS (High-Resolution Ten-Year Climate
Simulations): Final Report, 234 pp. [Available from MétéoFrance, Centre National de Recherches Météorologiques, 42 Ave. Gaspard Coriolis, 31059 Toulouse Cedex 01, France, or online at http://www.cnrm.meteo.fr/hiretycs/final_report.htm.]

Sadourny, R., and K. Laval, 1984: January and July performance of the LMD general circulation model. New Perspectives in Climate Modeling, A. Berger and C. Nicolis, Eds., Elsevier Press, 173197.

Talagrand, O., 1997: Assimilation of observations, an introduction. J. Meteor. Soc. Japan, 75, 191-209.

van den Broeke, M. R., 2000: On the interpretation of Antarctic temperature trends. J. Climate, 13, 3885-3889. 